\title{
Minor salivary gland mucoepidermoid carcinoma in children and adolescents: a case series and review of the literature
}

\author{
Priyanshi Ritwik ${ }^{1 *}$, Kitrina G Cordell ${ }^{2}$ and Robert B Brannon ${ }^{2}$
}

\begin{abstract}
Introduction: Because well-documented cases of mucoepidermoid carcinomas that are of minor salivary gland origin and occur in children and adolescents have rarely been reported, little information regarding their clinical features and biologic behavior is available. This case report represents a retrospective clinical analysis of five minor salivary gland mucoepidermoid carcinomas accessioned from a 35-year period at the Louisiana State University School of Dentistry and combines the data with 15 well-documented cases from the English language literature.

Case presentation: The five mucoepidermoid carcinomas in patients from birth to 19 years of age accounted for $1.3 \%$ of the accessioned minor salivary gland neoplasms. There were an additional 15 well-documented cases in the literature. Combining the data for the 20 mucoepidermoid carcinomas resulted in a mean age of 13.5 years and a 2.3:1 female-to-male ratio. Collectively, the hard palate, soft palate, and hard palate/soft palate junction accounted for $85 \%$ of the cases. Thirty-five percent of the cases presented as a fluctuant submucosal swelling with surface color alterations. The average duration was five months, and bone involvement occurred in seven cases. A histologic grade of low to intermediate predominated (95\%). Surgical removal was the treatment in all cases. Thirteen cases had adequate follow-up of three years or more, and recurrence was documented in only one case. There were no cases of death or metastasis in this series.

Conclusions: In children and adolescents, mucoepidermoid carcinomas have a female predilection and occur most commonly on the hard or soft palate or both. A fluctuant submucosal lump with a bluish color is a helpful diagnostic clue. The histologic grades of most mucoepidermoid carcinomas in the first and second decades of life are low and, to a lesser degree, intermediate. Complete surgical excision is the treatment of choice and results in a recurrence rate of less than $10 \%$.
\end{abstract}

\section{Introduction}

The relative frequency of epithelial salivary gland tumors occurring in children and adolescents ranges from 3.7\% to $5.5 \%$ [1]. Moreover, the high incidence of malignancy in minor salivary gland tumors is well established. Batsakis [2], in a review of the literature, determined that $52.3 \%$ of minor salivary gland tumors were malignant. Similar findings, of from $44 \%$ to $65 \%$, have been reported [3-8]. Therefore, the overall incidence of minor salivary gland neoplasms is low in the pediatric-adolescent age

\footnotetext{
* Correspondence: pritwi@lsuhsc.edu

'Department of Pediatric Dentistry, Louisiana State University Health Sciences Center School of Dentistry, 1100 Florida Avenue, Box 139, New Orleans, LA 70119, USA

Full list of author information is available at the end of the article
}

group, but in view of their high incidence of malignancy, their importance should not be underestimated.

The most common type of malignant salivary gland neoplasm of epithelial (parenchymal) origin in the pediatric-adolescent age group is the mucoepidermoid carcinoma (MEC) [9]. Other types of minor salivary gland adenocarcinomas in this age group are rarely reported. Most of the malignant neoplasms are found in the parotid gland; only a few pediatric and adolescent cases have been well documented in the minor glands [9]. In fact, a review of the English language literature revealed only 15 well-documented cases of MEC of minor salivary gland origin in this age group [1,10-19]. A search of the Louisiana State University School of Dentistry (LSUSD) Division of Oral and Maxillofacial

\section{Biomed Central}


Pathology archives of a 35-year period supports the paucity of malignant intraoral salivary gland tumors and the reported frequency of MECs in the first two decades of life. Therefore, the purposes of this retrospective analysis were to investigate the clinical features and biologic behavior of minor salivary gland MECs occurring in children and adolescents (from birth to 19 years of age) from the LSUSD and to compare these findings with well-documented cases reported in the English language literature.

In this study, the age of the pediatric-adolescent population was from birth to 19 years, which represents the first two decades of life. Minor salivary gland MECs from this age group were selected from the LSUSD Department of Oral and Maxillofacial Pathology archives of the period of 1 January 1969 to 31 December 2004. The Louisiana State University Health Sciences Center (LSUHSC) Institutional Review Board (\#6450) approved the research protocol. Demographic and clinical information was recorded for each case, and the histopathologic slides were reviewed by one of the authors (RBB). The LSUSD MECs were histologically graded by using the criteria set forth by Auclair et al. [20]. The LSUHSC School of Public Health Louisiana Tumor Registry provided follow-up information for the LSUSD cases.

A search of the English language medical and dental literature was performed for well-documented minor salivary gland MEC cases in the pediatric and adolescent age group. The search was carried out in Medline for 'mucoepidermoid carcinoma and salivary gland carcinoma', and limits were set to human subjects under 19 years and the English language. The search was last updated in September 2011. Once studies were identified, individual articles and their references were checked for additional studies. It should be noted that although investigators have published numerous series on salivary gland neoplasms, they provide an age range only. They do not correlate the age of the patient to the location of the lesion or offer other demographic and clinical information, such as the identity of the specific minor salivary gland involved. Some of these series did indicate that at least one patient was in the first or second decade of life; however, we did not include them in this study, because they lacked adequate detail [8,21-37]. Central (intraosseous) MECs of the maxilla and mandible were not included in this study.

\section{Case presentation Prevalence}

A total of 396 minor salivary gland neoplasms were accessioned at LSUSD from the 35-year period. Of these 396 cases, 14 (3.5\%) were benign and malignant neoplasms from patients in the first or second decade of life.
Five $(35.7 \%)$ of the 14 neoplasms were malignant; all were MECs.

A search of the English language literature revealed 15 well-documented cases of MEC in the minor salivary glands of children younger than 19 years of age [1,1019]. These data were combined with the information from the five LSUSD cases. Table 1 displays a summary of the demographics, clinical findings, treatment, and follow-up of the 15 well-documented minor salivary gland MECs in the literature, in addition to the five new LSUSD cases.

\section{Summary of findings}

The age range of the 20 patients was one and a half to 19 years, the mean was 13.5 years, and peak incidence was at the age of 14 years (Figure 1). Five (25\%) occurred in patients from birth to 12 years of age but only two of those were in the first decade of life (Figure 1). Of the 11 patients for whom race was known, nine (82\%) were white and two (18\%) were black. The female-to-male ratio was 2.3:1. The most common locations for the 20 tumors were the hard or soft palate or both $(85 \%)$, the buccal mucosa (10\%), and the upper lip (5\%). The site distribution of the lesions is shown in Figure 2. Detailed clinical features were often lacking or scant. Most were described as 'lumps' or submucosal nodules, 12 were non-ulcerated, three were ulcerated, three were firm to palpation with pink or flesh-colored surfaces, and seven were fluctuant with surface color alterations ranging from a light blue hue to purplish. The size of the tumor, in 13 cases, ranged from 0.5 to $5 \mathrm{~cm}$ and the mean size was $2 \mathrm{~cm}$. Resorption of bone at the site of the lesion occurred in three (15\%) cases, bone was not involved in nine (45\%) cases, and bone involvement was not stated in eight (40\%) cases. In those patients in whom tumor duration was reported, nine had an average duration of five months. Two patients, a 22-year-old man and a 19-year-old man, reported durations of seven years and 'forever', respectively. The histologic grade was provided in 19 cases: 12 (63\%) low-grade, four (21\%) low- to intermediate-grade, two (11\%) intermediategrade, and one $(5 \%)$ poorly differentiated. Representative lesions stained with hematoxylin and eosin are shown in Figures 3 and 4 at low magnification and in Figures 5 and 6 at high magnification. Treatment was surgical removal in all cases. Surgical modalities varied from case to case, depending, in part, on the local extent of tumor involvement with the soft tissues or bone (or both), lymph node status, and the tumor's histologic grade (Table 1).

Thirteen cases had adequate follow-up ranging from three to 21 years, and the mean follow-up duration was 7.9 years. One case from the literature reported recurrence, to indicate a recurrence rate of $7.7 \%$ for the 
Table 1 Mucoepidermoid carcinomas

\begin{tabular}{|c|c|c|c|c|c|c|c|c|c|c|}
\hline Source & $\begin{array}{l}\text { Age, } \\
\text { years }\end{array}$ & Gender & Site & Duration & $\begin{array}{l}\text { Size, } \\
\mathrm{cm}\end{array}$ & $\begin{array}{l}\text { Bone/LN } \\
\text { Involvement }\end{array}$ & Histologic grade & Treatment & $\begin{array}{l}\text { Recurrence/ } \\
\text { Interval }\end{array}$ & Follow-up \\
\hline Tipton [10] & 1.5 & Male & Buccal mucosa & NS & 1.0 & NS & Poorly differentiated & Wide local excision & No & NED 6 years \\
\hline Budnick [11] & 12 & Female & Hard palate & NS & 2.0 & Bone: NSLN: NS & Low & Excision down to bone & No & NED 3 years \\
\hline Gustafsson et al. [12] & 13 & Female & Hard palate & 2 months & 1.5 & Bone: NoLN: NS & Low & Resection of the tumor & No & NED 1.5 years \\
\hline Lack and Upton [13] & 18 & Female & Upper lip ${ }^{a}$ & NS & NS & Bone: NSLN: NS & $\begin{array}{l}\text { Low to focally } \\
\text { intermediate }\end{array}$ & Near total maxillectomy & No & NED 8 years \\
\hline Fonseca et al. [1] & 14 & Male & Soft palate & NS & NS & Bone: NSLN: No & Low & 1st surgery2nd surgery & Yes/5 years & NED, NS \\
\hline Fonseca et al. [1] & 14 & Female & Soft palate & NS & NS & Bone: NSLN: No & Low & Surgery & No & NED 6 months \\
\hline April et al. [14] & 10 & Female & $\begin{array}{l}\text { Junction of the } \\
\text { hard/soft palate }\end{array}$ & $\begin{array}{l}\text { Nasal congestion } \\
\times 1 \text { month }\end{array}$ & 0.5 & $\begin{array}{l}\text { Bone: erosion into } \\
\text { left naresLN: No }\end{array}$ & Intermediate & NS & NS & NS \\
\hline Aguiar et al. [15] & 13 & Female & $\begin{array}{l}\text { Junction of the } \\
\text { hard/soft palate }\end{array}$ & 7 months & 3.0 & Bone: NoLN: No & NS & Excision & No & NED 4 months \\
\hline Winslow et al. [16] & 10 & Female & Buccal mucosa & NS & NS & Bone: NoLN: No & Intermediate & Wide local excision & NS & NS \\
\hline Flaitz [17] & 8 & Male & Hard palate & 9 months & 2.0 & Bone: NoLN: No & Low & $\begin{array}{l}\text { Wide local excision down } \\
\text { to periosteum }\end{array}$ & NS & NS \\
\hline $\begin{array}{l}\text { Caccamese and } \\
\text { Ord [18] }\end{array}$ & 17 & Male & $\begin{array}{l}\text { Left junction of the } \\
\text { hard/soft palate }\end{array}$ & NS & 1.5 & Bone: NoLN: No & Low & Local resection & No & NED 94 months \\
\hline $\begin{array}{l}\text { Caccamese and } \\
\text { Ord [18] }\end{array}$ & 14 & Female & Hard palate & 1 month & 1.0 & Bone: NoLN: No & Low to intermediate & Excision & No & NED 62 months \\
\hline $\begin{array}{l}\text { Caccamese and } \\
\text { Ord [18] }\end{array}$ & $22^{\mathrm{b}}$ & Male & Palate, NOS & 7 years & 2.0 & Bone: NoLN: No & Low & Excision with $1.0 \mathrm{~cm}$ margins & No & NED 34 months \\
\hline $\begin{array}{l}\text { Caccamese and } \\
\text { Ord [18] }\end{array}$ & 16 & Female & $\begin{array}{l}\text { Junction of the soft } \\
\text { palate and anterior pillar }\end{array}$ & 1 year & 2.5 & Bone: NoLN: No & Low to intermediate & Local resection & No & NED 42 months \\
\hline Moraes et al. [19] & 14 & Female & Left hard palate & 1 year & 5 & Bone: YesLN: No & Low & Transoral resection & No & NED 4 years \\
\hline LSUSD & 15 & Female & Left hard palate & 3 weeks & NS & Bone: NoLN: No & Low & Excision & No & NED 21 years \\
\hline LSUSD & 14 & Female & Right hard palate & NS & 3.0 & Bone: YesLN: NS & Low & Excision & No & NED 19 years \\
\hline LSUSD & 15 & Female & Left hard palate & NS & NS & Bone: NSLN: NS & Low & NS & No & NED 9 years \\
\hline LSUSD & 18 & Female & Left hard palate & 3 weeks & NS & Bone: NSLN: NS & Low & Excision & No & NED 8 years \\
\hline LSUSD & 19 & Male & $\begin{array}{l}\text { Right junction of the } \\
\text { hard/soft palate }\end{array}$ & 'Forever' & 2.0 & $\begin{array}{l}\text { Bone: NoLN: } \\
\text { NoLungs: No }\end{array}$ & Low to intermediate & $\begin{array}{l}\text { Wide surgical excision } \\
\text { with 'alveolar bone biopsy' }\end{array}$ & No & NED 2 years \\
\hline
\end{tabular}

a Reported as 'buccal sulcus anteriorly in the premaxillary area'. 'Lesion followed for seven years (since the age of 15). LSUSD, Louisiana State University School of Dentistry; LN, lymph node; NED, no evidence of disease; NOS, not further specified; NS, not stated. 


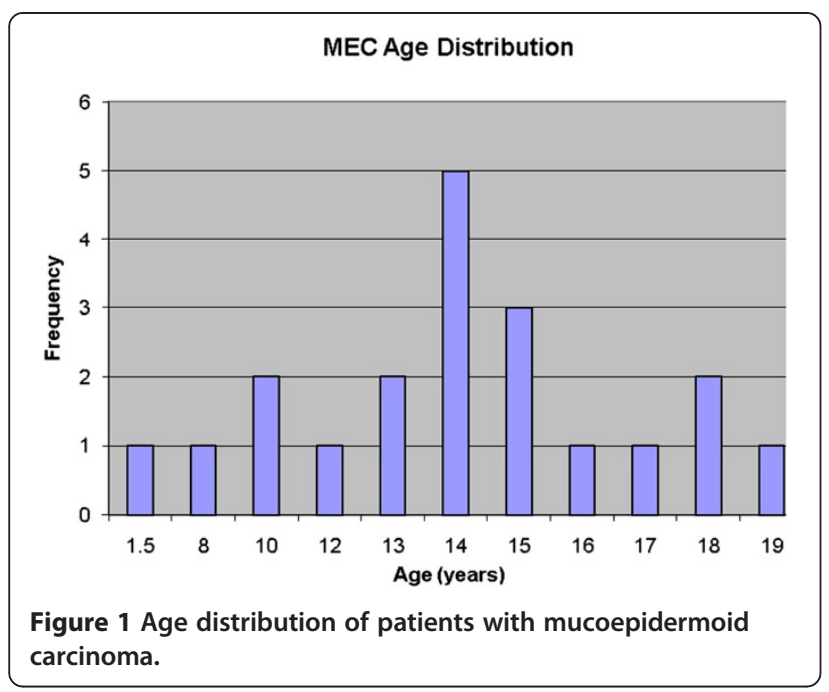

20 cases reviewed. There were no cases of death or metastasis in this series.

\section{Discussion}

Epithelial neoplasms originating in the minor salivary glands account for approximately $15 \%$ of all salivary gland neoplasms $[6,38]$. It has been estimated that about $1 \%$ to $5 \%$ of all salivary gland tumors develop in children and adolescents $[1,8]$, and MEC is the most common malignancy $[5,9,39,40]$. In the current LSUSD series, $3.5 \%$ of the epithelial minor salivary gland neoplasms occurred in patients 19 years of age or younger; this is in close agreement with the series reported by Waldron et al. [38] and Kusama et al. [41], who found incidences of $3.7 \%$ and $5.4 \%$, respectively. A total of five malignant salivary gland tumors, all MECs, represented 1.3\% of all salivary gland tumors accessioned in the LSUSD oral biopsy service from a 35-year period, and this supports the conclusion in the literature that MEC is the most

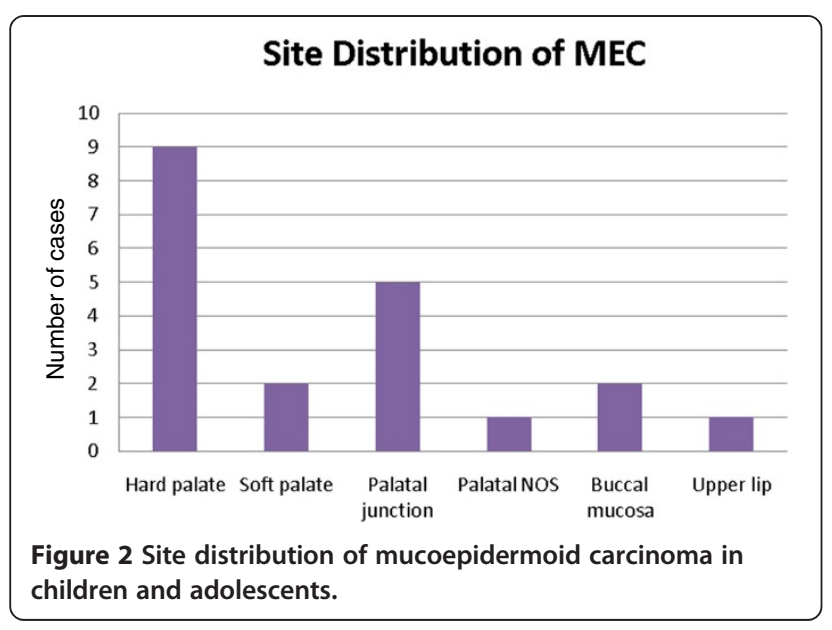

common malignancy of minor salivary glands in the first and second decades of life.

This study combined data from five LSUSD cases and 15 cases from the literature for data analysis. The majority of epithelial salivary gland neoplasms occur late in childhood, after 10 years of age [42]. MECs are generally found between the ages of 10 and 16 years [40,43], which is in general agreement with this case report. In the 20 cases reviewed, 16 MECs occurred in the second decade and the overall average age was 13.5 years. We have included the case reported by Tipton [10] of a 20-month-old with a poorly differentiated MEC; however, in view of its poor documentation, we are not convinced that this tumor is an MEC. Nevertheless, we have included it since it has been frequently referenced as such. According to Mehta and Willging [40], MEC is the most common radiation-induced salivary gland tumor in children. None of the patients in this review had a history of radiation.

Among the 20 cases, there was a female predilection of $2.3: 1$. Since race was known in only $55 \%$ of the 20 cases, no further analysis of this demographic feature was undertaken. This series confirmed that the hard or soft palate (or both) is by far the most common site for intraoral minor salivary gland MECs, followed by the buccal mucosa [39].

The histologic grade of the MEC often reflects the clinical manifestations of the tumor. Intraorally, lowgrade MECs tend to be asymptomatic enlargements of prolonged duration. In this study, the average duration was five months before diagnosis; one case had a duration of seven years. Interestingly, seven of the lowgrade MECs appeared as fluctuant light blue or purplish submucosal lumps, thus resembling the reactive salivary gland mucocele (mucous retention phenomenon). The reason they possess similar clinical appearances is that low-grade MECs and mucoceles possess mucous cyst formation and mucous pseudocyst formation, respectively. As Flaitz [17] has pointed out, the differential diagnosis for a compressible or fluctuant light blue mass in an intraoral salivary gland-bearing area in a child or adolescent should include reactive and neoplastic lesions, and MEC and mucocele should be at the top of the list. Although MECs are considered rare in the childrenadolescent age group, they must be considered when a lesion appears to be similar to a mucocele but is found at a site other than the lower lip mucosa [17].

Histologically, MECs are divided into low-, intermediate-, and high-grade types, which correlate to clinical behavior. Our analysis of the five LSUSD cases was consistent with that of several other studies [1,11-19] in that all of the low- to intermediate-grade MECs originating from intraoral minor salivary glands had a very low recurrence rate and a high survival rate (100\%). 


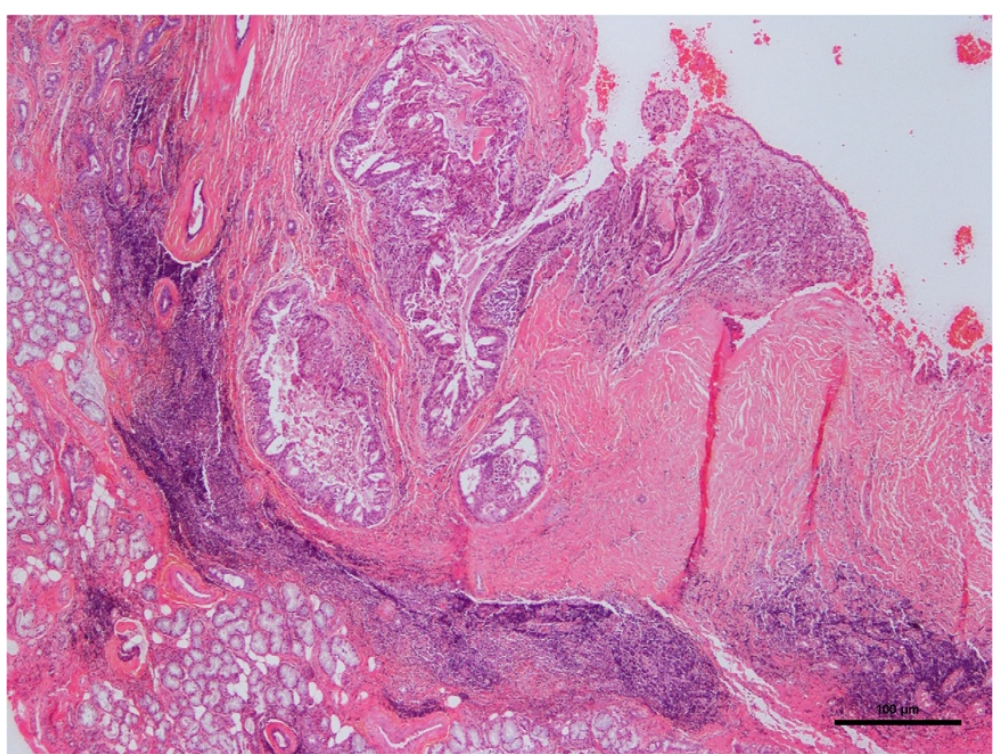

Figure 3 Photomicrograph of hematoxylin-and-eosin-stained section of mucoepidermoid carcinoma.

Recurrence in this series was less than $10 \%$. This is in keeping with the general consensus that low- and intermediate-grade MECs have an indolent clinical course and a minimal chance for metastasis [14]. The current series supports the opinions that MEC in children appears to be somewhat more innocuous than in adults and that the probability of death for children with low-grade MEC is essentially zero [44]. However, others believe that malignant salivary gland malignancies in children exhibit biologic behavior similar to those occurring in adults and therefore require the same treatment principles as those occurring in adults [45,46]. Nevertheless, close clinical follow-up should be long-term, as outlined by April et al. [14], because low- to intermediate-grade MECs in this age group can recur many years after initial removal $[1,14]$.

The results of this study and others [17-19] suggest that low- to intermediate-grade MECs originating from intraoral minor salivary glands in children and adolescents can be effectively managed by wide local surgical excision that ensures tumor-free surgical margins. Wide surgical excision in combination with bone removal is

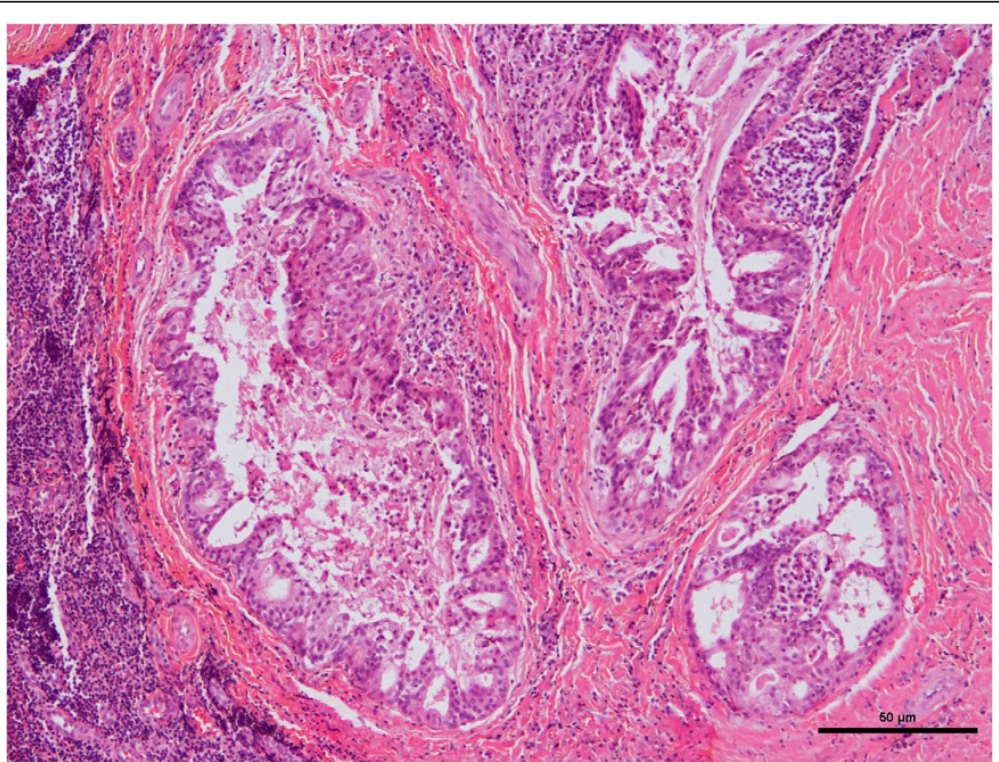

Figure 4 Photomicrograph of hematoxylin-and-eosin-stained section of mucoepidermoid carcinoma. 


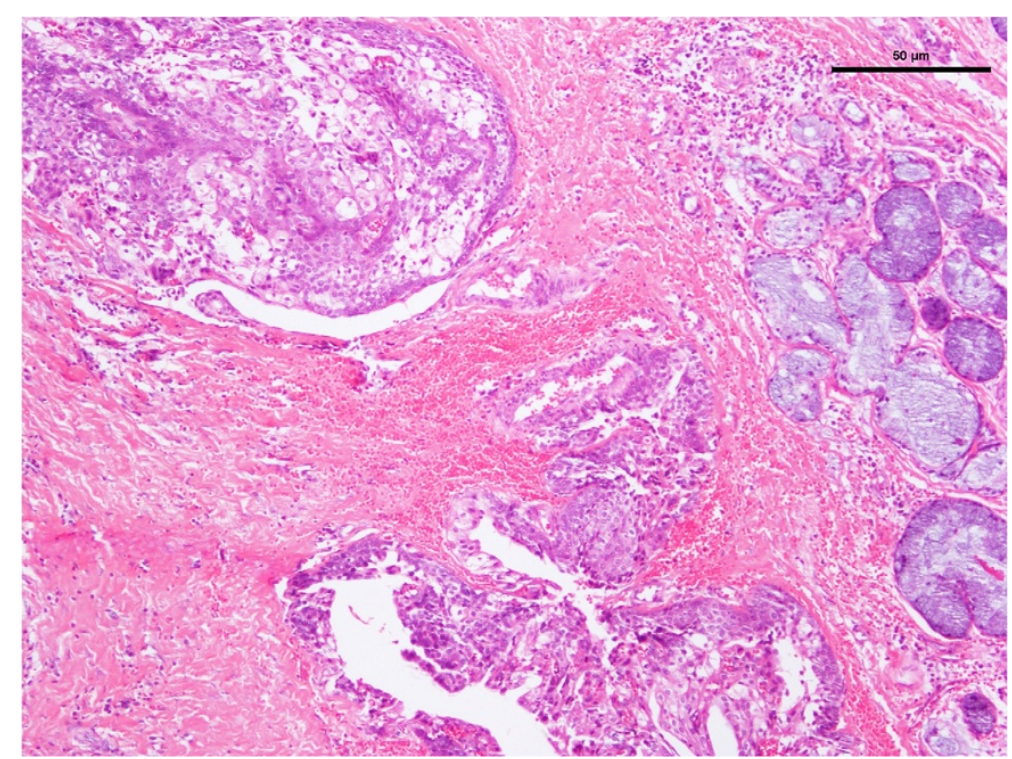

Figure 5 Photomicrograph of hematoxylin-and-eosin-stained section of mucoepidermoid carcinoma.

preferred only when there is gross periosteal involvement or bone erosion by the MEC $[17,18]$.

It is most likely that the treating dentist would take an intraoral radiograph or an orthopantomograph or both at the time of the initial clinical presentation. However, the treating oral surgeon would need a computed tomography scan to establish the extent of the lesion prior to surgical exploration. Prognosis of the lesion on the basis of imaging modalities has not been investigated, and to date, the only prognostic indicator is the histopathologic grading of the lesion [14].

\section{Conclusions}

MECs have a female predilection and are decidedly uncommon in the first decade of life. MECs have a high predilection for the hard or soft palate or both. Fluctuance and a light blue color are helpful diagnostic clinical clues. MEC must be considered in the differential diagnosis of a lump or mass in a salivary gland-bearing area, especially the palate. The histologic grades of most MECs in the first and second decades of life are low and, to a lesser degree, intermediate. Complete surgical excision is the initial

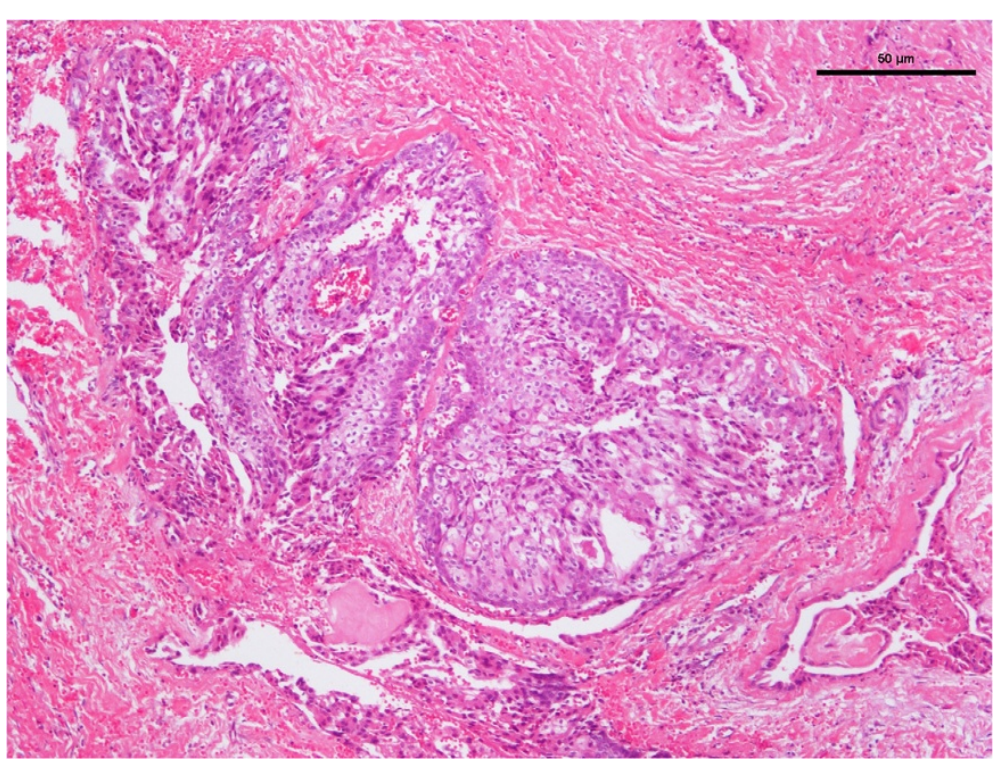

Figure 6 Photomicrograph of hematoxylin-and-eosin-stained section of mucoepidermoid carcinoma. 
treatment of choice and results in a recurrence rate of less than $10 \%$ in this series.

\section{Competing interests}

The authors declare that they have no competing interests.

\section{Authors' contributions}

PR helped to review the clinical and histopatholgic data from the selected cases and the literature and to analyze the data. RBB helped to review the clinical and histopatholgic data from the selected cases and the literature and to analyze the data, reviewed histopathologic microslides, and confirmed the diagnoses for the cases from the LSUSD series. KGC provided the photomicrographs of the histopathologic slides. All authors read and approved the final manuscript.

\section{Acknowledgments}

We wish to acknowledge Elizabeth Strother, associate director for Dental Library Services of the LSUSD, for her assistance in the preparation of this case report.

\section{Author details}

Department of Pediatric Dentistry, Louisiana State University Health Sciences Center School of Dentistry, 1100 Florida Avenue, Box 139, New Orleans, LA 70119, USA. ${ }^{2}$ Division of Oral and Maxillofacial Pathology, Louisiana State University Health Sciences Center School of Dentistry, 1100 Florida Avenue, New Orleans, LA 70119, USA.

\section{Received: 6 November 2011 Accepted: 18 April 2012}

Published: 3 July 2012

\section{References}

1. Fonseca I, Martins AG, Soares J: Epithelial salivary gland tumors of children and adolescents in southern Portugal: a clinicopathologic study of twenty-four cases. Oral Surg Oral Med Oral Pathol 1991, 72:696-701.

2. Batsakis JG: Tumors of the Head and Neck: Clinical and Pathological Considerations. 2nd edition. Baltimore: Williams \& Wilkins; 1979:77.

3. Yih WY, Kratochvil FJ, Stewart JC: Intraoral minor salivary gland neoplasms: review of 213 cases. J Oral Maxillofac Surg 2005, 63:805-810.

4. Pires FR, Pringle GA, de Almeida OP, Chen SY: Intra-oral minor salivary gland tumors: a clinicopathologic study of 546 cases. Oral Oncol 2007, 43:463-470.

5. Seifert G, Okabe H, Caselitz J: Epithelial salivary gland tumors in children and adolescents: analysis of 80 cases (salivary gland register 1965-1984). ORL 1986, 48:137-149.

6. Eveson JW, Cawson RA: Tumours of the minor (oropharyngeal) salivary glands: a demographic study of 336 cases. J Oral Pathol 1985, 14:500-509.

7. Auclair PL, Ellis GL, Gnepp DR, Wenig BM, Janney CG: In Salivary gland neoplasms: general considerations. In Surgical Pathology of the Salivary Glands. Edited by Ellis GL, Auclair PL, Gnepp DR. Philadelphia: Saunders; 1991:35-164.

8. Yu GY, Li ZL, Ma DQ, Zhang Y: Diagnosis and treatment of epithelial salivary gland tumours in children and adolescents. Br J Oral Maxillofac Surg 2002, 40:389-392.

9. Luna MA, Batsakis JG, el-Naggar AK: Salivary gland tumors in children. Ann Otol Rhinol Laryngol 1991, 100:869-871.

10. Tipton JB: Carcinoma of the minor salivary gland in an 18-month old child: a case report. Plast Reconstr Surg 1978, 62:790-792.

11. Budnick SD: Minor-salivary-gland tumors in children. ASDC J Dent Child 1982, 49:44-47.

12. Gustafsson H, Dahlqvist A, Anniko M, Carlsoo B: Mucoepidermoid carcinoma in a minor salivary gland in childhood. J Laryngol Otol 1987 101:1320-1323.

13. Lack EE, Upton MP: Histopathologic review of salivary gland tumors in childhood. Arch Otolaryngol Head Neck Surg 1988, 114:898-906.

14. April MM, Brodsky LS, Cunningham MJ, Harari PM, Harrison L, Poje CP: Mucoepidermoid carcinoma in a 10-year-old girl. Head Neck 1997, 19:431-435

15. Aguiar MC, Dayrell CQ, Mesquita RA: Palatal mucoepidermoid carcinoma in a child. J Clin Pediatr Dent 1998, 22:347-349.

16. Winslow CP, Batuello $S$, Chan KC: Pediatric mucoepidermoid carcinoma of the minor salivary glands. Ear Nose Throat J 1998, 77:390-391. 395.
17. Flaitz CM: Mucoepidermoid carcinoma of the palate in a child. Pediatr Dent 2000, 22:292-293.

18. Caccamese JF, Ord RA: Paediatric mucoepidermoid carcinoma of the palate. Int J Oral Maxillofac Surg 2002, 31:136-139.

19. Moraes P, Pereira C, Almeida O, Perez D, Correa ME, Alves F: Paediatric intraoral mucoepidermoid carcinoma mimicking a bone lesion. Int $J$ Pediatr Dent 2007, 17:151-154.

20. Auclair PL, Goode RK, Ellis GL: Mucoepidermoid carcinoma of intraoral salivary glands: evaluation and application of grading criteria in 143 cases. Cancer 1992, 69:2021-2030.

21. Brown L, Everett BL, Girardeau HS: Tumors of the minor salivary glands. Cancer 1959, 12:40-46.

22. Richardson GS, Dickayson WL: Tumors of salivary glands. An analysis of 752 cases. Plast Reconstr Surg 1975, 55:131-138.

23. Schuller DE, McCabe BF: Salivary gland neoplasms in children Otolaryngol. Clin North Am 1977, 19:399-412.

24. Pogrel MA: Tumors of the salivary glands: a histological and clinical review. Br J Oral Surg 1979, 17:47-56.

25. O'Brien CJ, Soong SJ, Herrera GA, Urist MM, Maddox WA: Malignant salivary tumors- analysis of prognostic factors and survival. Head Neck Surg 1986, 9:82-92.

26. Cunningham MJ, Myers EN, Bluestone CD: Malignant tumors of the head and neck in children: a twenty year review. Int J Pediatr Otolaryngol 1987, 13:279-292.

27. McWhirter WR, Stiller CA, Lennox EL: Carcinomas in childhood. A registrybased study of incidence and survival. Cancer 1989, 63:2242-2246.

28. Taiwo EO, Salako NO, Sote EO: Distribution of oral tumors in Nigerian children based on biopsy materials over an 11-year period. Community Dent Oral Epidemiol 1990, 18:200-203.

29. Das S, Das AK: A review of pediatric oral biopsies from a surgical pathology service in a dental school. Pediatr Dent 1993, 15:208-211.

30. Ulmansky M, Lustmann J, Malkin N: Tumors and tumor-like lesions of the oral cavity and related structures in Israeli children. Int $J$ Oral Maxillofac Surg 1999, 28:291-294.

31. Maaita JK: Oral tumors in children: a review. J Clin Pediatri Dent 2000 24:133-135.

32. Bentz BG, Hughes A, Ludemann P, Maddalozzo J: Masses of the salivary gland region in children. Arch Otolaryngol Head Neck Surg 2000, 126:1435-1439.

33. Al-Khateeb T, Hamasha AA, Almasri NM: Oral and maxillofacial tumors in North Jordanian children and adolescents: a retrospective analysis over 10 years. Int J Oral Maxillofac Surg 2003, 32:78-83.

34. Wang D, Li Y, He H, Liu L, Wu L, He Z: Intraoral minor salivary gland tumors in a Chinese population: a retrospective study on 737 cases. Oral Surg Oral Med Oral Pathol Oral Radiol Endod 2007, 104:94-100.

35. Gbotolorun OM, Arotiba GT, Effion OA, Omitola OG: Minor salivary gland tumors in a Nigerian Hospital: a retrospective review of 146 cases. Odontostomatol Trop 2008, 31:17-23.

36. de Oliveira FA, Duarte EC, Taveira CT, Máximo AA, de Aquino EC, Alencar $R$ Vencio EF: Salivary gland tumor: a review of 599 cases in a Brazilian population. Head Neck Pathol 2009, 3:271-275.

37. Adeyemi BF, Ogun GO, Akang EE: Retrospective analysis of intraoral salivary gland tumors in Ibadan Nigeria West. Afr Med 2010, 29:98-103.

38. Waldron CA, El-Mofty SK, Gnepp DR: Tumors of the intraoral minor salivary glands: a demographic and histologic study of 426 cases. Oral Surg Oral Med Oral Pathol 1988, 66:323-333.

39. Goode RK, El-Naggar AK: In Mucoepdermoid carcinoma, World Health Organization Classification of Tumours: Pathology and Genetics of Head and Neck Tumours. Edited by Barnes L, Eveson JW, Reichart P, Sidransky D. Lyon: IARC Press; 2005:219-220

40. Mehta D, Willging JP: Pediatric salivary gland lesions. Semin Pediatr Surg 2006, 15:76-84.

41. Kusama K, Iwanari S, Aisaki K, Wada M, Ohtani J, Itoi K, Hanai K, Shimizu K, Komiyama K, Kudo I, Moro I: Intraoral minor salivary gland tumors: a retrospective study of 129 cases. J Nihon Univ Sch Dent 1997, 39:128-132.

42. Woolley AL: Salivary gland diseases in children. Curr Opin Otolaryngo Head Neck Surg 1996, 4:385-391.

43. Bradley P, McClelland L, Mehta D: Paediatric salivary gland epithelial neoplasms. ORL 2007, 69:137-145.

44. Conley J, Tinsley PP: Treatment and prognosis of mucoepidermoid carcinoma in the pediatric age group. Arch Otolaryngol 1985, 111:322-324. 
45. Batsakis JG, Regezi JA: The pathology of head and neck tumors: salivary glands, part 4. Head Neck Surg 1979, 1:340-349.

46. Baker SR, Malone B: Salivary gland malignancies in children. Cancer 1985, 55:1730-1736

doi:10.1186/1752-1947-6-182

Cite this article as: Ritwik et al: Minor salivary gland mucoepidermoid carcinoma in children and adolescents: a case series and review of the literature. Journal of Medical Case Reports 2012 6:182.

\section{Submit your next manuscript to BioMed Central} and take full advantage of:

- Convenient online submission

- Thorough peer review

- No space constraints or color figure charges

- Immediate publication on acceptance

- Inclusion in PubMed, CAS, Scopus and Google Scholar

- Research which is freely available for redistribution 